\title{
UNA DÉCADA DE INVESTIGACIÓN EMPÍRICA SOBRE EL LIDERAZGO EDUCATIVO EN CHILE. UNA REVISIÓN SISTEMÁTICA DE LOS ARTÍCULOS PUBLICADOS EN REVISTAS INDEXADAS (2008- 2019)
}

\author{
José Weinstein ${ }^{1}$, Gonzalo Muñoz ${ }^{2}$, Matías Sembler ${ }^{3}$ y \\ Javiera Marfán ${ }^{4}$
}

\section{RESUMEN}

En la última década, en Chile se ha puesto en marcha una serie de políticas destinadas a fomentar el liderazgo educativo. Sin embargo, poco se sabe acerca de las características de la investigación que se ha realizado en esta temática. Esta revisión topográfica analiza de manera sistemática los artículos en torno al liderazgo educativo en Chile, que cuentan con una base de investigación empírica y que fueron publicados en revistas indexadas en el período comprendido entre 2008 y 2019. Los resultados muestran que se han publicado 47 artículos, con un aumento sustantivo desde el año 2016 en adelante. Dichos artículos han sido publicados por un grupo de 85 autores, no obstante, la mayoría de ellos solo ha publicado un artículo. Las investigaciones se caracterizan por ser mayoritariamente descriptivas y cualitativas, siendo escasas las que han realizado muestreo de tipo aleatorio o que han explotado los datos secundarios existentes. Un $40 \%$ de los artículos declara no haber contado con recursos para desarrollar su investigación. Los focos de investigación más estudiados han sido los directores, así como las escuelas municipales. Las publicaciones se han concentrado en revistas latinoamericanas e indexadas en Scopus. La caracterización realizada permite considerar al campo de estudio como emergente, sugiriéndose un conjunto de medidas que permitirían su consolidación.

Conceptos clave: Chile, liderazgo educativo, revisión sistemática.

\section{A DECADE OF EMPIRICAL RESEARCH ON EDUCATIONAL LEADERSHIP IN CHILE. A SYSTEMATIC REVIEW OF ARTICLES PUBLISHED IN INDEXED JOURNALS (2008-2019)}

\author{
ABSTRACT
}

In the last decade in Chile, the government and institutions have launched different policies designed to promote educational leadership. However, little is known about the characteristics

1 Universidad Diego Portales, Santiago, Chile. Contacto: jose.weinstein@udp.cl

2 Universidad Diego Portales, Santiago, Chile. Contacto: gonzalo.munozs@mail.udp.cl

3 Universidad Diego Portales, Santiago, Chile. Contacto: matias.sembler@mail.udp.cl

4 University of Cambridge, Cambridge, Reino Unido: jm2159@cam.ac.uk 
of the research done on this topic. This topographical review has systematically analyzed the articles on educational leadership in Chile, which have an empirical research base, and which have been published in indexed journals between 2008 and 2019. The results reveal that 47 articles have been published, with an increasing number from the year 2016 onwards. These articles were published by a group of 85 authors, the majority of whom have only published one article. The studies are characterized as mostly descriptive and qualitative, with few that have done random samples or that exploited the existing secondary data. Approximately $40 \%$ of the articles declare they did not receive financial support develop their research. The most studied research focuses were school leaders, as well as municipal (public) elementary schools. The publications reviewed are concentrated in Scopus indexed and Latin American journals. The characterization made allows us to consider as emergent, research on the field of school leadership, and to suggest a set of measures that would allow its consolidation.

Key concepts: Chile, school leadership, systematic review.

\section{Introducción}

En la última década, distintos gobiernos han desplegado diferentes políticas referidas a potenciar y extender el rol de los directivos en la conducción educativa de los establecimientos escolares. De esta manera, se ha generado un marco de actuación (Marco para la buena dirección y el liderazgo escolar, Ministerio de Educación de Chile, Mineduc, 2015) que define lo que los directivos deben realizar; se ha creado un sistema de reclutamiento y selección de directores profesionalizado y con participación de instancias públicas especializadas (el Servicio Civil); y se han dado mayores atribuciones a los directivos respecto de la conducción del establecimiento que encabezan (en ámbitos tales como la conformación de su equipo de confianza, la contratación y despido de docentes, la conducción del plan de mejoramiento educativo, o el desarrollo profesional de los docentes) (Centro de Desarrollo y Liderazgo Educativo, CEDLE, 2016; Organización para la Cooperación y el Desarrollo Económicos, OCDE, 2017). En paralelo, durante estos años se han desarrollado importantes iniciativas para potenciar la preparación de los directivos escolares, a través de diferentes planes financiados por el Mineduc, para tal efecto, desde un programa denominado "Formación de directores de excelencia" (2010) hasta la creación de dos centros académicos interuniversitarios dedicados exclusivamente al fomento del liderazgo directivo (Muñoz, Amenábar y Valdebenito, 2019). 
Este conjunto de iniciativas de política, si bien no siempre ha sido coherente entre sí, destaca en el panorama de América Latina, en que muchos sistemas escolares aún no han siquiera profesionalizado la labor directiva (Murillo, 2012; Organización de las Naciones Unidas para la Educación Ciencia y Cultura, Unesco, 2014; Weinstein y Hernández Vejar, 2014). Sin embargo, hasta el momento no se sabe cuánta ni qué tipo de evidencia es la que ha estado tras estas políticas emergentes.

En términos generales, el real alcance de la investigación especializada en esta temática en el país es una pregunta abierta. Es cierto que recientemente se han publicado las primeras dos revisiones de literatura especializada (Aravena \& Hallinger, 2018; Flessa, Bramwell, Fernández \& Weinstein, 2018) en torno a la investigación de liderazgo educativo en América Latina, y ambas han coincidido respecto de la importancia de la participación de Chile dentro del concierto regional — contribuyendo con más de un tercio del total-. Sin embargo, en ambos casos se advierte que esta relevancia de la producción chilena en torno a este tema debe ser vista de manera relativa y con mucha cautela, puesto que las cifras absolutas delatan una escasa producción regional al respecto. Es así como Aravena y Hallinger (2018) muestran que el conjunto de los artículos publicados por toda América Latina en las principales revistas indexadas no constituye más del 1\% del total. Se trata, en consecuencia, de un incipiente liderazgo regional de Chile dentro de un campo emergente de investigación educativa (Flessa et al., 2018). Adicionalmente, estas revisiones cuantifican el aporte chileno, pero no lo cualifican en términos de la caracterización del conocimiento producido ni tampoco de su influencia regional.

El presente artículo tiene por objeto describir la investigación que se ha realizado en Chile en torno al liderazgo educativo entre los años 2008 y 2019, con un foco específico en los estudios que han buscado levantar evidencia empírica respecto del tema. Interesa saber cuánto se ha investigado en torno al liderazgo que efectivamente despliegan los actores educativos, en especial los directivos, en las escuelas y liceos, de modo de calibrar mejor los avances realizados. Para ello, se ha desarrollado una revisión sistemática 
de la investigación existente de manera que, usando métodos transparentes y explícitos de selección y análisis de la producción publicada en revistas indexadas, se ha buscado caracterizar el campo de estudio emergente (Hallinger, 2013; 2014). Como primer paso, ha interesado desarrollar una revisión sistemática topográfica, que sea capaz de describir (o mapear) las características formales que posee la investigación en torno al liderazgo educativo en Chile (Hallinger \& Bryant, 2013). Una revisión topográfica permite no solo detallar la producción realizada y la evidencia disponible, sino que también develar las zonas de oscuridad existentes, permitiendo orientar las necesidades de investigación que el campo debiese abordar en el futuro (Aravena y Hallinger, 2018).

Las preguntas que orientan el desarrollo de este trabajo pueden sintetizarse en una interrogante general: A partir de los artículos publicados en revistas indexadas, ¿qué características posee la investigación empírica en torno al liderazgo educativo que se ha desarrollado en Chile en la última década? Esta pregunta mayor se despliega en cuatro más específicas:

- ¿Cuánto se ha investigado empíricamente en torno al liderazgo educativo en Chile entre los años 2008 y 2019 y quiénes (instituciones e investigadores) lo han realizado?

- ¿Qué se ha investigado en términos de las dimensiones del liderazgo educativo, así como de los actores y los niveles del sistema escolar considerados?

- ¿Cómo se ha realizado, desde un punto de vista metodológico, dicha investigación?

- ¿Dónde, considerando las revistas educativas indexadas, se ha publicado esta investigación?

La relevancia de este artículo radica en su objetivo, el cual busca caracterizar por primera vez y de manera sistemática la investigación con base empírica existente acerca de liderazgo educativo en Chile. Al realizar una identificación de los estudios publicados y analizar sus contenidos, se sistematiza y pone a disposición de futuras investigaciones el conjunto de materiales existentes. Al hacerlo, se permite que las nuevas investigaciones en liderazgo educativo puedan 
realizarse de manera acumulativa. Por otra parte, se propone una metodología de trabajo para llevar a cabo la revisión topográfica que puede ser útil para investigaciones semejantes que se desarrollen en Chile en el futuro, la que también podría emplearse en otros países latinoamericanos. Por último, al visibilizar el conjunto de materiales publicados en revistas indexadas, se fomenta el uso de evidencia producida localmente en la formulación de políticas educativas nacionales en esta temática, apoyando así la mejora en su pertinencia y contextualización.

El artículo inicia caracterizando el marco metodológico de liderazgo educativo que se ha empleado, para luego explicitar los pasos dados al realizar esta revisión sistemática. Luego se describen los resultados principales encontrados, siguiendo las distintas preguntas de investigación ya enunciadas. Finalmente, se formula un conjunto de conclusiones y se proponen algunos temas de discusión, incluyendo las temáticas de investigación que parecen prioritarias de ser abordadas en el futuro.

\section{Marco metodológico}

\subsection{Foco, dimensiones y variables del estudio}

Las revisiones sistemáticas aportan significativamente en la caracterización de un campo de investigación, pues informan qué es lo que se conoce, cómo se ha accedido a dicho conocimiento y cómo varían las investigaciones tanto en los resultados obtenidos como en las metodologías aplicadas (Gough, Oliver \& Thomas, 2017). Su función prospectiva radica en la capacidad de generar una perspectiva más completa de un tema de estudio, respecto de lo que sería posible obtener a partir de investigaciones individuales, siendo clave para la definición de futuros objetivos de producción de conocimiento. Esto, toda vez que la comprensión en cuanto a qué es lo que se conoce y qué es lo que aún no se ha investigado en un campo de estudio, constituye un insumo indispensable para plantear nuevas agendas de investigación.

La revisión sistemática que se presenta en este artículo corresponde a un tipo particular de revisión, conocida como revisión 
topográfica, las que a diferencia de las temáticas, no profundizan en los resultados de las investigaciones, sino que caracterizan aspectos como el volumen de investigación en un determinado campo, los modelos conceptuales en que se inscriben los artículos revisados, los métodos de investigación aplicados y los temas o preguntas de investigación abordadas (Aravena y Hallinger, 2018; Hallinger, 2013).

Esta revisión, en particular, concentró su atención en cuatro dimensiones y ámbitos de las publicaciones de liderazgo escolar que se han producido en Chile en el período 2008-2019. La Tabla 1 presenta sintéticamente las dimensiones y variables principales que se han considerado en esta revisión. El detalle de cada una de ellas se puede ir coligiendo de la lectura específica de la sección de resultados de este artículo.

Tabla 1

Mapa de la revisión topográfica realizada

\begin{tabular}{|c|c|c|}
\hline Dimensión & Descripción & Variables analizadas \\
\hline $\begin{array}{l}\text { Cuánto } \\
\text { y desde } \\
\text { dónde se } \\
\text { investiga }\end{array}$ & $\begin{array}{l}\text { Esta dimensión da cuenta de } \\
\text { algunos aspectos básicos de } \\
\text { los artículos, que permiten } \\
\text { caracterizar su volumen, autoría } \\
\text { y origen institucional, entre } \\
\text { otros factores relevantes. }\end{array}$ & $\begin{array}{l}\text { - Número de publicaciones. } \\
\text { - Año de publicación. } \\
\text { - Autores involucrados. } \\
\text { - Origen institucional de las } \\
\text { publicaciones. } \\
\text { - Fuente de financiamiento de las } \\
\text { investigaciones. }\end{array}$ \\
\hline $\begin{array}{l}\text { Qué se } \\
\text { investiga }\end{array}$ & $\begin{array}{l}\text { Esta dimensión aborda los } \\
\text { principales temas que se han } \\
\text { estudiado, así como también } \\
\text { el tipo de preguntas de } \\
\text { investigación que han intentado } \\
\text { responder las publicaciones y } \\
\text { el objeto de estudio (a nivel de } \\
\text { actores y centros) de las mismas. }\end{array}$ & $\begin{array}{l}\text { - Carácter de las investigaciones } \\
\text { (descriptivas, relacionales, explicativas). } \\
\text { - Foco de las investigaciones } \\
\text { (antecedentes, prácticas y/o efectos } \\
\text { de liderazgo). } \\
\text { - Prácticas de liderazgo estudiadas (de } \\
\text { acuerdo con el Marco para la buena } \\
\text { dirección, Mineduc, 2015). } \\
\text { - Actores en los que se enfocan los } \\
\text { artículos. } \\
\text { - Tipos de centros educativos estudiados } \\
\text { - (dependencia y niveles educativos). } \\
\text { Enfoques de liderazgo presentes en las } \\
\text { - investigaciones. } \\
\text { Autores de referencia para las } \\
\text { publicaciones. }\end{array}$ \\
\hline
\end{tabular}




\begin{tabular}{|c|c|c|}
\hline $\begin{array}{l}\text { Cómo } \\
\text { investiga }\end{array}$ & $\begin{array}{l}\text { se Esta dimensión da cuenta de } \\
\text { las principales definiciones } \\
\text { metodológicas realizadas por } \\
\text { los estudios publicados, en } \\
\text { términos de su diseño general, } \\
\text { las muestras investigadas y los } \\
\text { instrumentos aplicados. }\end{array}$ & $\begin{array}{l}\text { - Diseños de investigación } \\
\text { (cuantitativos, cualitativos y mixtos). } \\
\text { - Muestras utilizadas (tipo de muestra y } \\
\text { número de actores). } \\
\text { - Tipos de instrumentos aplicados. }\end{array}$ \\
\hline $\begin{array}{l}\text { Dónde } \\
\text { publica }\end{array}$ & $\begin{array}{l}\text { se Esta dimensión refiere al espacio } \\
\text { donde han sido publicados } \\
\text { los trabajos nacionales sobre } \\
\text { liderazgo, tanto en términos de } \\
\text { la indexación de revistas como } \\
\text { de alguna de sus características. }\end{array}$ & $\begin{array}{l}\text { - Tipo de revistas (indexación). } \\
\text { - Idioma. } \\
\text { - Factores de impacto. }\end{array}$ \\
\hline
\end{tabular}

Fuente: Elaboración propia.

\subsection{Definiciones metodológicas}

El primer desafío de esta revisión fue definir el universo de publicaciones a considerar, para lo cual se estimó un conjunto de criterios de inclusión y exclusión. En primer término, temáticamente, se consideraron aquellos artículos que habían investigado el liderazgo educativo en contextos escolares. En segundo lugar, respecto del tipo de fuente, se consideraron artículos escritos en español o en inglés, publicados en revistas indexadas en sistemas Web of Science, WoS (actual Clarivate, incluyendo el catálogo Emerging Source Citation Index, ESCI), Scopus y SciELO (Scientific Electronic Library Online). En tercer lugar, en relación con el período de tiempo revisado, se consideraron los artículos publicados desde el año 2008 hasta el momento de efectuada la búsqueda (marzo de 2019)5. Por su parte, los criterios de exclusión refirieron principalmente al tipo de publicaciones, debido a que se estableció como objetivo central de esta primera revisión analizar los estudios y publicaciones que hubieran generado evidencia empírica. Por ello, se excluyeron del marco de este análisis las revisiones sistemáticas, artículos teóricos, validación

5 Se definió como punto de partida el año 2008 debido a que en ese momento, por primera vez, el ámbito del liderazgo escolar se transformó en una línea de investigación con financiamiento público, fruto de la creación de los centros de investigación avanzada en educación. Ese año, por ejemplo, fue creado el Centro de Políticas y Prácticas en Educación (CEPPE), coordinado por la Pontificia Universidad Católica de Chile y conformado también por otras instituciones como Fundación Chile, que consideró formalmente un componente de investigación en torno al liderazgo directivo, con financiamiento de tres años para su ejecución. 
de escalas y todas aquellas investigaciones que no consideraran al liderazgo de actores escolares como foco o informantes de los estudios en la base de las publicaciones.

Respecto del procedimiento de búsqueda, los términos utilizados fueron "Leadership" y "Chile", lo que fue complementado por los términos "Education", "Principal" y "School", relativos específicamente al ámbito educativo. Se probaron sus distintas combinaciones y se utilizaron los mismos términos en español. La búsqueda se realizó en las bases de datos WoS-Clarivate Analytics, Scopus y SciELO. Se buscó en idioma inglés y español en todos los buscadores. La búsqueda efectuada, durante marzo de 2019, permitió rastrear inicialmente 181 resultados para el período de tiempo analizado.

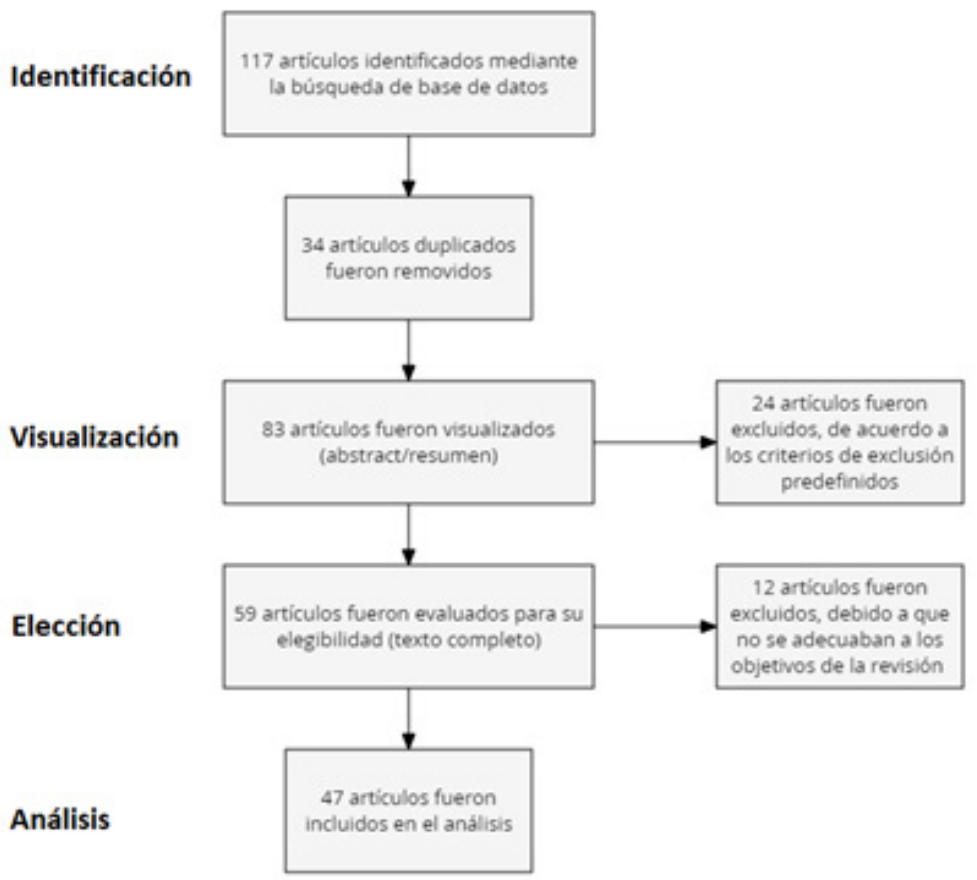

Figura 1. Proceso de búsqueda de artículos.

Fuente: Elaboración propia. 
La Figura 1 grafica el proceso de búsqueda, considerando sus distintas fases de inclusión y exclusión de artículos, siguiendo las orientaciones del protocolo PRISMA (Moher, Liberati, Tetzlaff $\&$ Altman, 2009). De los 181 resultados encontrados, 117 correspondieron a artículos vinculados con el liderazgo en contextos escolares, los cuales disminuyeron a 83, tras haber sido eliminados los duplicados entre bases de datos. Fueron revisados los resúmenes de aquellos 83 artículos y se excluyeron los que no se ajustaban a los criterios definidos, ya fuera por el tipo de estudio, o bien, por no considerar a actores escolares como foco o informantes. Posteriormente, de los 59 artículos restantes se eliminaron otros 12, tras indagar en sus textos completos y confirmar que el abordaje del liderazgo resultaba meramente secundario o porque correspondían a investigaciones de distintos sistemas escolares en América Latina, sin entregar resultados específicos respecto de las escuelas chilenas, sino solo conclusiones generales. Finalmente, fueron incluidos en el análisis 47 artículos (los que se describen en el Anexo 1).

En cuanto a la generación de información base para esta revisión sistemática, se elaboró en primer lugar una ficha de lectura para el análisis topográfico de los artículos seleccionados, la cual consideró sus características generales (nombre, autor, año, idioma, palabras clave, objetivos, financiamiento), de sus autores (número, género, procedencia, instituciones a las que pertenecen), de las revistas en que fueron publicados (nombre, tipo de revista, indexaciones, país), de sus marcos conceptuales (tipos de liderazgo y autores más citados), de sus metodologías (tipo de estudio, diseño general, actores foco, actores informantes, muestreo, tamaño de muestra, dependencia y nivel de enseñanza de establecimientos incluidos, instrumentos de generación de información, procedimientos de análisis), y de sus tipos de hallazgos (antecedentes, prácticas y efectos). Para realizar un análisis comparativo se definió un conjunto de categorías para las distintas variables mencionadas (Gough et al., 2017). Cabe señalar que la ficha fue validada a partir del vaciado simultáneo de un conjunto de artículos por parte de los revisores, lo que permitió agregar variables que no habían sido incluidas inicialmente y corregir categorías de respuesta que no se adecuaban a la evidencia encontrada en los artículos revisados. 
Finalmente, respecto del análisis de la información obtenida, luego de la revisión y fichado de cada uno de los 47 artículos, se generó una base de datos en Excel con la información sistematizada. Se realizó en primer término un análisis estadístico descriptivo de cada una de las variables consideradas en la revisión. Dicho análisis tuvo un componente univariado, orientado a caracterizar el cuerpo de artículos según las distintas variables generadas, y otro componente bivariado, a través del cual se logró comparar temporalmente y según tipo de estudio, las investigaciones y publicaciones revisadas. Para realizar este análisis se utilizó el paquete estadístico SPSS 24.0 (IBM Corp., 2016). El análisis que se presenta en este artículo corresponde a una síntesis de los hallazgos más relevantes asociados directamente con la pregunta central de la revisión sistemática.

\section{Resultados}

\section{1. ¿Cuánto y quiénes han publicado?}

Fueron 47 artículos en total de liderazgo educativo y que contienen recolección y análisis de evidencia empírica, publicados en el período considerado (2008 a 2019) en revistas indexadas WoS, Scopus y SciELO.

Estos artículos siguen una distribución temporal en la que se produce un salto del patrón de producción anual desde 2016 en adelante. Como puede verse en la Figura 2, se pasa de una exigua publicación anual — de no más de tres artículos por año—, a alrededor de 10 , con un crecimiento de más de 300\%. La tendencia de tres o menos artículos es sostenida en el tiempo (durante ocho años) y el nuevo patrón también se ha mantenido constante (durante los tres años considerados ${ }^{6}$ ). Debido a este cambio mayor se ha realizado, como podrá apreciarse más adelante, una comparación de distintos aspectos entre los artículos publicados en ambos períodos.

6 Debe recordarse que el estudio no considera el primer trimestre del año 2019, por lo cual no se ha consignado dicho año en la figura. 


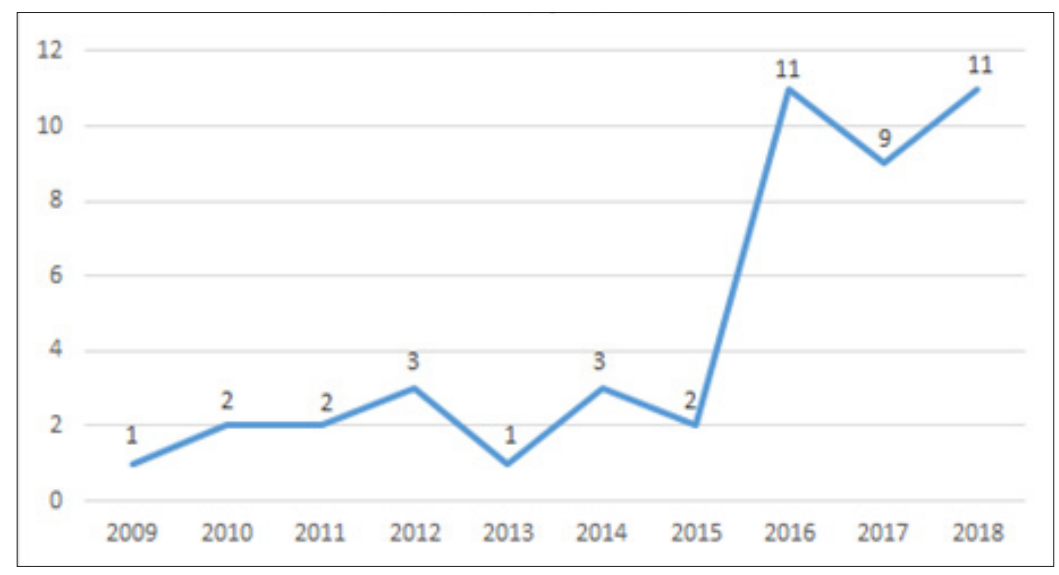

Figura 2. Número de artículos por año. Fuente: Elaboración propia.

Estos 47 artículos han sido producidos por 85 investigadores e investigadoras. Desde un punto de vista de género, hay un predominio masculino: $55 \%$ son hombres, $45 \%$ son mujeres. Es importante constatar que dicha proporción se mantiene inalterada cuando se analizan las primeras autorías de los artículos, no existiendo un sesgo de género al respecto.

En términos de grados académicos, los autores y autoras que publican en revistas indexadas tienen muy mayoritariamente estudios de posgrado. Es así como un 51\% detenta el grado de Doctor. Le sigue un 22\% de magísteres, un 15\% de candidatos(as) a Doctor, y solo un $4 \%$ de los autores no tiene títulos de posgrado ${ }^{7}$.

En cuanto a la cantidad de artículos que han publicado, hay una importante mayoría de autores y autoras que solo ha publicado un artículo en materia de liderazgo educativo (64 investigadores solo han publicado un artículo en revistas indexadas). Entre los que han publicado más de un artículo, se cuenta con 11 que han publicado dos artículos y 10 entre tres y siete artículos. Entonces, parece posible distinguir entre un núcleo pequeño de investigadores que han hecho de esta temática un ámbito de cierta especialización respecto de una

7 Existe un $8 \%$ de autores que no reporta su grado académico. 
mayoría en la cual su permanencia en el estudio del tema es aún incierta.

En cuanto a la procedencia de los autores y autoras, destaca la alta incidencia de los que trabajan fuera de la Región Metropolitana —que constituyen la mayoría, con 51\%-. Igualmente debe considerarse la presencia de un grupo minoritario de 11 autores y autoras que se desempeñan en universidades extranjeras y que han participado de coautorías internacionales.

Desde el punto de vista institucional, la mayoría de la producción ha sido generada por universidades privadas del Consejo de Rectores (CRUCH), como se muestra en la Figura 3.

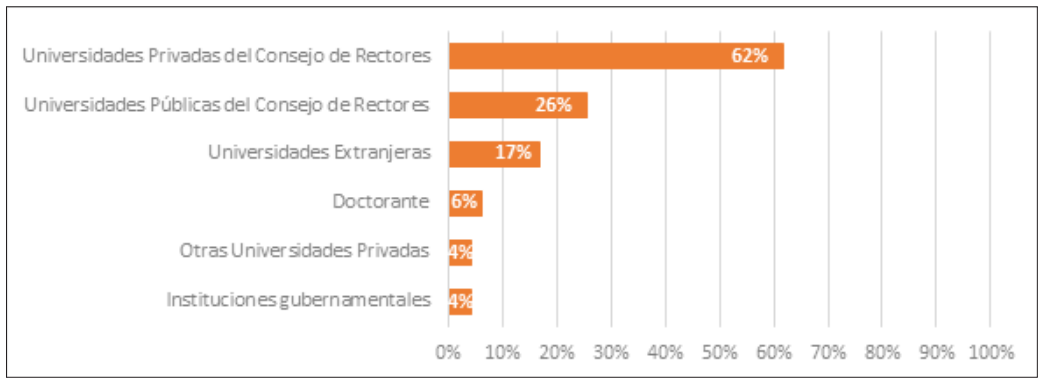

Figura 3. Tipo de institución a la que pertenecen los autores.

Fuente: Elaboración propia.

Conviene destacar que dos universidades privadas del CRUCH, la Universidad Católica de Valparaíso (UCV) y la Universidad Diego Portales (UDP), ocupan los primeros lugares en la producción de artículos en revistas indexadas. De hecho entre ambas suman prácticamente la mitad del total de lo publicado: 23 artículos. La alta incidencia de estas dos universidades es una constante del conjunto del período analizado, es decir, ambas son igualmente influyentes tanto antes como después del "salto adelante" de productividad científica constatado desde 2016. En el otro extremo, se destaca un número significativo de universidades que brindan magísteres en liderazgo y gestión escolar ${ }^{8}$ y que, sin embargo, no tienen un solo artículo publicado en alguna revista indexada, planteándose una

8 La información respecto de los magísteres y estudios de posgrado de liderazgo y gestión que se brindan en Chile puede encontrarse en Muñoz et al., 2019. 
interrogante mayor respecto de si realizan algún tipo de investigación al respecto.

En términos de coautoría internacional, un 21\% de los artículos corresponde a la cooperación entre autores y autoras de instituciones nacionales con sus colegas de instituciones internacionales. Los investigadores afiliados a universidades extranjeras que más artículos han publicado se encuentran en la Universidad Autónoma de Barcelona y en la Universidad de Barcelona, con dos cada una. Son muy escasos (4\%) los artículos escritos exclusivamente por académicos de instituciones internacionales y que no han sido producidos en asociación con académicos que trabajan en instituciones chilenas. Los artículos de coautoría internacional son, en un número equivalente, de autores de la Región Metropolitana o de otras regiones del país. En contrapartida, llama la atención que prácticamente no se producen coautorías nacionales entre autores de la Región Metropolitana con autores de otras regiones del país.

En cuanto a las fuentes de financiamiento con que han contado estas investigaciones, como muestra la Figura 4, más del 40\% declara no haber tenido algún tipo de apoyo financiero. Igualmente, se ratifica el aporte procedente del Fondo Nacional de Desarrollo Científico y Tecnológico (Fondecyt), entre los financiamientos del sector público, el que cubre alrededor de un tercio de los estudios realizados. El fondo específico para financiar investigaciones con que cuenta el Mineduc —el Fondo de Investigación y Desarrollo en Educación (Fonide) — ha brindado un muy escaso aporte al estudio del liderazgo. Es importante considerar, como se verá luego, que el financiamiento disponible impacta en el tipo de estudio realizado y el tipo de indexación de la revista en la que se publica. 


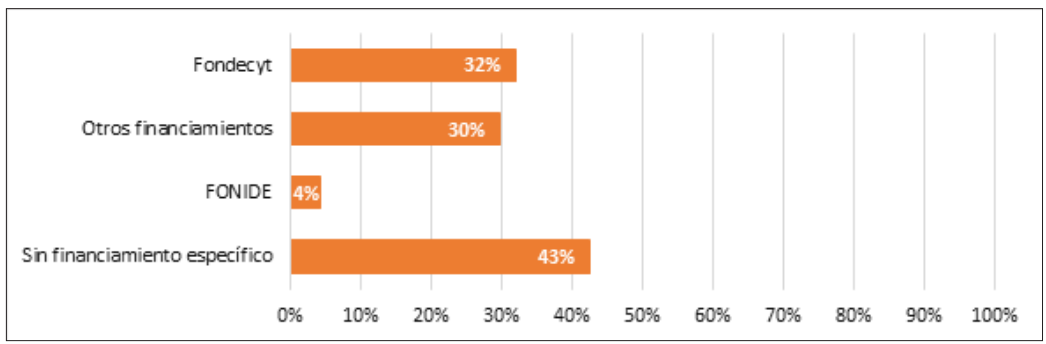

Figura 4. Fuentes de financiamiento de las investigaciones Fuente: Elaboración propia.

\section{2. ¿Qué se ha investigado de liderazgo escolar en Chile?}

Esta sección busca caracterizar algunos aspectos centrales de las investigaciones publicadas en torno al liderazgo escolar. Sin profundizar propiamente en los hallazgos, se describe cuáles han sido los objetivos principales de los estudios, cuáles son sus focos de atención, qué referentes conceptuales han considerado los investigadores e investigadoras respecto del liderazgo escolar y, finalmente, cuáles son los actores y tipos de centros educativos que han sido objeto de las investigaciones.

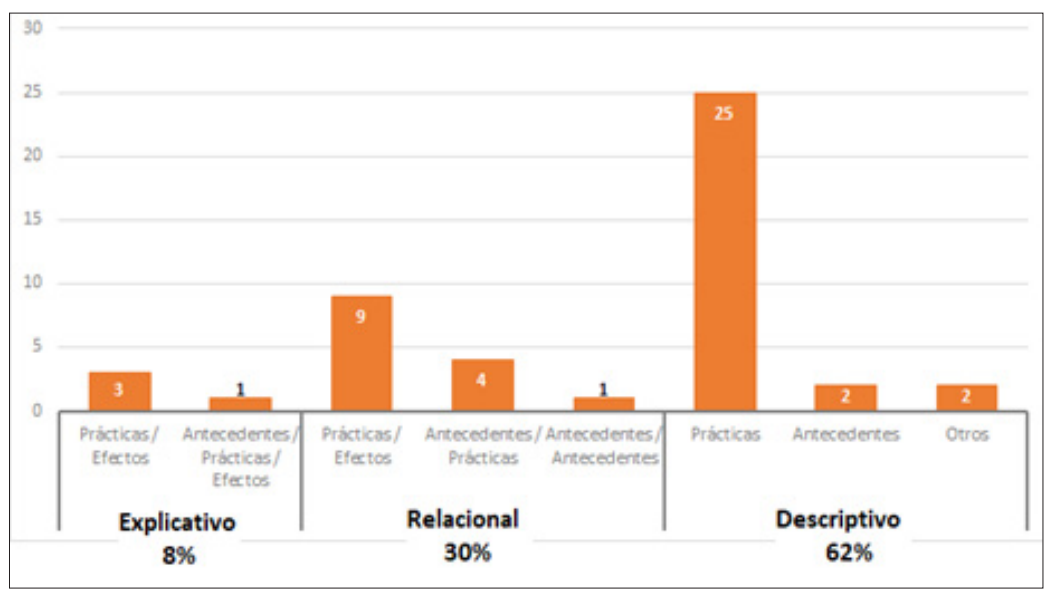

Figura 5. Alcances de la investigación.

Fuente: Elaboración propia.

Respecto del alcance de las investigaciones, la revisión realizada arroja como primer resultado relevante que prácticamente dos tercios de las publicaciones persiguieron un objetivo de carácter descriptivo, 
con su foco puesto en dar cuenta de algunas características básicas del liderazgo escolar, sin pretensión de establecer ni relación ni causalidad con otras variables determinantes o con los efectos del trabajo asociado a las funciones directivas. Como puede apreciarse en la Figura 6, solamente un 8\% de las publicaciones declaró un objetivo de tipo causal, mientras que un 30\% de ellas estableció alguna relación entre el liderazgo y sus antecedentes (por ejemplo, relación entre ciertas prácticas de liderazgo y el nivel formativo de los líderes), entre el liderazgo y sus efectos a nivel de la organización escolar, los docentes o los estudiantes ${ }^{9}$.

En cuanto al foco de las investigaciones publicadas, se distinguen aquellas que se concentraron en analizar ciertos antecedentes del liderazgo, las que se centraron en las prácticas y ejercicio del liderazgo escolar mismo, las que observaron y concluyeron los efectos que dichas prácticas han tenido, y aquellas que se enfocaron en la conexión entre alguno de estos elementos. Al respecto, la revisión arrojó que la gran mayoría de los estudios descriptivos se centraron en describir las prácticas de liderazgo escolar en los centros escolares, mientras que entre los estudios relacionales y explicativos la mayoría de las publicaciones priorizó la relación entre estas prácticas de liderazgo y sus efectos, sobre todo a nivel de la organización escolar y los docentes ${ }^{10}$.

Para avanzar un paso más, todas las publicaciones fueron analizadas desde la perspectiva de las dimensiones de práctica que el Marco para la buena dirección (Mineduc, 2015) establece ${ }^{11}$. Cómo

9 Los estudios revisados fueron categorizados en función de sus objetivos en tres tipos (Hernández-Sampieri, Fernández Collado y Baptista Lucio, 2010): 1) Descriptivo, orientado a describir de manera sistemática una situación, problema, fenómeno o programa, o proveer información sobre las condiciones en las que vive una comunidad, o dar cuenta de las actitudes en torno a un determinado tema; 2) Correlacional, orientado a descubrir o establecer la existencia de una relación, asociación o interdependencia entre dos o más aspectos de una situación; y 3) Explicativo o causal, orientado a explicar por qué y cómo se produce la relación entre dos aspectos de una situación o fenómeno.

10 Una menor proporción de estudios analiza la relación entre liderazgo escolar y algunas variables a nivel de los estudiantes (como su desempeño en pruebas estandarizadas).

11 El Marco para la buena dirección es un instrumento público cuyo objetivo es orientar el accionar y el desarrollo profesional de los directivos escolares. Define cinco dimensiones de práctica que son útiles para analizar los focos de las investigaciones sobre el tema en Chile: 1) Construyendo e implementando una visión estratégica compartida; 2) Desarrollando 
puede apreciarse en la Figura 6, se destaca que todas las dimensiones de dicho documento han recibido cierta atención por parte de los investigadores. Sin embargo, se ha puesto un foco comparativamente mayor en la dimensión de "liderando y monitoreando los procesos de enseñanza aprendizaje" (53\%), seguida por las dimensiones "desarrollando y gestionando la organización" y "construyendo e implementando una visión estratégica compartida" (45\% y 43\%, respectivamente). Por su parte, las dimensiones "desarrollar las capacidades profesionales" y "gestionar la convivencia y la participación de la comunidad escolar" (30\% y 34\%, respectivamente) son las que tienen una presencia menor. En este sentido la investigación especializada se ha hecho eco de la orientación que las políticas educacionales han ido entregando respecto de la importancia de un liderazgo escolar con foco en los procesos pedagógicos (Núñez, Weinstein y Muñoz, 2010).

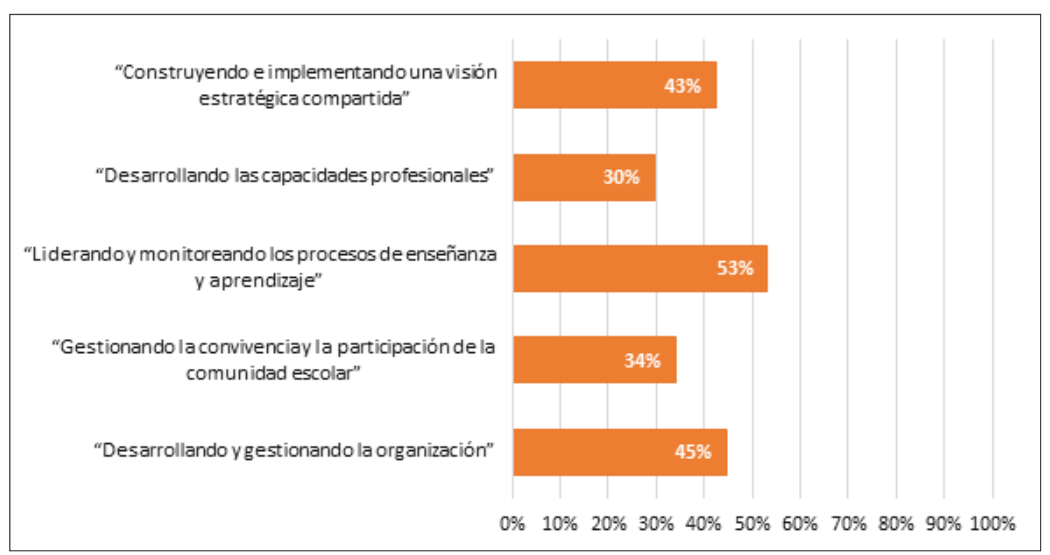

Figura 6. Temáticas de las investigaciones.

Fuente: Elaboración propia.

¿Cuáles son los referentes académicos que han guiado las investigaciones? Para identificarlos se realizó una cuantificación de los principales autores citados en las publicaciones, frente a lo cual se

las capacidades profesionales; 3) Liderando y monitoreando los procesos de enseñanza y aprendizaje; 4) Gestionando la convivencia y la participación de la comunidad escolar; 5) Desarrollando y gestionando la organización. El detalle de este marco orientador puede encontrarse en https://liderazgoescolar.mineduc.cl/marco-para-la-buena-direccion-y-elliderazgo-escolar/ 
observó a los teóricos del liderazgo educativo más recurrentemente citados. Los datos muestran el significativo peso que han tenido ciertos autores y autoras en la investigación chilena: así Kenneth Leithwood (79\% de los artículos cita a este autor), Alma Harris (57\%) y Vivianne Robinson (43\%) destacan como los autores más referidos en los trabajos nacionales; seguidos por Phillip Hallinger (36\%), la OECD (36\%) y Michael Fullan (34\%). Respecto de los enfoques de liderazgo escolar que han guiado la investigación chilena, cerca del $47 \%$ de los artículos analizados utiliza como referente (conceptual y/o empírico) alguno o algunos de los enfoques reconocidos (Bush, $2016^{12}$ ). En estos casos, las perspectivas del liderazgo instruccional (17\%), transformacional (15\%) y distribuido (13\%) son los que mayor presencia han tenido en las publicaciones nacionales. Visto desde otra perspectiva, puede destacarse que una mitad de los artículos no declara una adhesión a un enfoque específico del liderazgo, ocupando de manera genérica dicho concepto.

Interesa ahora acercarse al qué se ha investigado, preguntándose por quiénes han sido los objetos principales de estudio, tanto en términos de los actores como del tipo de establecimientos que se ha priorizado.

En cuanto a los actores, es notorio que los directores y directoras de establecimientos han sido el principal foco de las investigaciones. En efecto, del total de publicaciones sistematizadas, más del 80\% considera a los directores como objeto de estudio, mientras que en más de la mitad de las investigaciones ellos son el único actor estudiado. Solamente un 15\% de las investigaciones se refiere a la realidad de los jefes de UTP y un porcentaje todavía menor aborda a otros directivos o a los equipos directivos como unidad ${ }^{13}$.

Si bien solamente un $13 \%$ de las investigaciones escoge a los profesores y su liderazgo como objeto de estudio (en general en términos de su relación con los directivos), en el 55\% de

12 Este autor define siete tipos de liderazgo, a saber: instruccional o para el aprendizaje, gestor, transformacional, moral (o auténtico), distribuido, docente y contingente.

13 Lo que se hizo en este caso fue identificar, para cada estudio, cuáles eran los actores que la investigación declaraba analizar y sobre el cual el artículo terminaba proveyendo evidencia. 
las publicaciones analizadas los docentes son una fuente de información de lo que se está estudiando. Los informantes clave de las investigaciones siguen siendo los directores (79\% de las publicaciones ${ }^{14}$ ), seguidos justamente por los docentes y por otros directivos (38\%). Solamente un $11 \%$ y $9 \%$ de las investigaciones considera a los estudiantes y a las familias, respectivamente, como actores relevantes para obtener información acerca del liderazgo escolar en Chile.

Tabla 2

Actores foco e informantes

\begin{tabular}{|c|c|c|}
\hline Actores & Foco & Informante \\
\hline Directores & $81 \%$ & $79 \%$ \\
\hline Jefe de UTP & $15 \%$ & $*$ \\
\hline Otros directivos & $13 \%$ & $38 \%$ \\
\hline Equipos directivos & $9 \%$ & $*$ \\
\hline Profesores & $13 \%$ & $55 \%$ \\
\hline Estudiantes & $2 \%$ & $11 \%$ \\
\hline Sostenedores & $2 \%$ & $9 \%$ \\
\hline Apoderados(as) & $0 \%$ & $9 \%$ \\
\hline
\end{tabular}

Nota: *Incluida dentro de categoría otros(as) directivos(as).

Fuente: Elaboración propia.

En cuanto al tipo de establecimiento que ha sido estudiado en la investigación especializada en liderazgo existe, en relación con la matrícula que congrega cada dependencia, una sobrerrepresentación de la educación pública en estos estudios y una subrepresentación de la educación privada. En efecto, casi la mitad de los estudios observa y analiza solamente la realidad del liderazgo en las escuelas públicas, mientras que un 13\% de los estudios investiga este fenómeno en paralelo en escuelas públicas y subvencionadas. Excepcionalmente, un $6 \%$ de los estudios se concentra exclusivamente en la educación particular subvencionada (que representa actualmente más del 55\% de la matrícula); y solo un cuarto de las publicaciones ha analizado al conjunto de las dependencias del sistema escolar chileno (público, privado subvencionado y privado pagado). Conviene advertir que existe cierta tendencia hacia una mayor representación en la

14 En un 28\% de los artículos, el único informante de la investigación es el director o directora. 
investigación de esta realidad mixta del sistema escolar chileno: así se han duplicado los estudios que abordan todas las dependencias en el ciclo 2016-2019 (pasando de un 15\% a 29\%), mientras que se han reducido significativamente los estudios que solamente estudian al sector municipal.

Tabla 3

Muestra de establecimientos según dependencia y nivel de enseñanza

\begin{tabular}{lrlr}
\hline \multicolumn{1}{c}{ Dependencia } & \multicolumn{2}{c}{ Nivel de enseñanza } \\
\hline Municipales & $49 \%$ & Básica & $30 \%$ \\
\hline Particulares subvencionados & $7 \%$ & Secundaria & $11 \%$ \\
\hline Particulares pagados & $2 \%$ & Inicial + básica & $2 \%$ \\
\hline Municipales + particulares subvencionados & $14 \%$ & Básica + secundaria & $28 \%$ \\
\hline $\begin{array}{l}\text { Municipales + particulares subvencionados } \\
+ \text { particulares pagados }\end{array}$ & $28 \%$ & Inicial + básica + secundaria & $4 \%$ \\
\hline
\end{tabular}

Fuente: Elaboración propia.

Respecto de los niveles educativos cubiertos por las investigaciones, el hallazgo más relevante es que, del total de estudios que reportan esta variable ${ }^{15}$, la mayoría de ellos se concentra solamente en la educación básica, o bien, en establecimientos que incorporan tanto educación básica como secundaria. Solamente un $11 \%$ de los estudios analiza la realidad particular del liderazgo en la enseñanza media, y es menor todavía el porcentaje de investigaciones que estudian este fenómeno en la educación inicial (6\%). Esta distribución no ha variado significativamente entre los períodos 2008-2015 y 2016-2019.

\section{3. ¿Cómo se ha investigado?}

Desde un punto de vista metodológico, la caracterización de los artículos analizados se centra en cuatro ejes: diseño general, muestreo, técnicas de producción de información, y tipos de análisis. En primer lugar, se realiza una caracterización metodológica general del cuerpo de los artículos. Posteriormente, se ahonda, desde una perspectiva comparativa, en sus especificidades según correspondan a estudios de tipo cuantitativo, cualitativo o mixto.

15 Un $28 \%$ no lo hace. 
Cabe señalar que entre los 47 artículos revisados se observa un predominio de los estudios cualitativos (40\%) respecto de los cuantitativos (34\%), el que se acentúa respecto de aquellos estudios que se basan en metodologías mixtas (26\%). Igualmente, el tipo de estudio publicado ha variado significativamente en el período analizado, debido al crecimiento que ha ido experimentado la publicación de investigaciones mixtas ${ }^{16}$.

Tabla 4

Diseño metodológico del cuerpo de artículos revisados

\begin{tabular}{|c|c|c|c|}
\hline Diseño general & Muestreo & Técnicas & Análisis \\
\hline $\begin{array}{l}\text { Estudio de caso: } 53 \% \\
(25) \text {. } \\
\text { Encuesta: } 26 \%(12) \text {. } \\
\text { Análisis de datos } \\
\text { secundarios: } 6 \%(3) \\
\text { Estudio de caso + } \\
\text { Encuesta: } 15 \%(7)\end{array}$ & $\begin{array}{l}\text { No aleatorio: } 66 \% \\
(31) \text {. } \\
\text { Aleatorio: } 23 \%(11) \text {. } \\
\text { No reportado: } 11 \% \\
(5) \text {. }\end{array}$ & $\begin{array}{l}\text { Entrevistas: } 55 \%(26) \text {. } \\
\text { Cuestionarios: } 53 \% \\
\text { (25). } \\
\text { Espacios grupales: } \\
\text { 36\% (17). } \\
\text { Observación: } 17 \% \text { (8). } \\
\text { Uso de datos } \\
\text { secundarios: } 17 \%(8) .\end{array}$ & $\begin{array}{l}\text { Cualitativo de } \\
\text { discursos: } 66 \% \text { (31). } \\
\text { Estadística } \\
\text { descriptiva: } 45 \% \\
\text { (21). } \\
\text { Estadística } \\
\text { correlacional y } \\
\text { multivariada: } 38 \% \\
\text { (18). }\end{array}$ \\
\hline
\end{tabular}

Fuente: Elaboración propia.

Respecto del total de artículos, sobresale la preponderancia que cobra el estudio de casos en los diseños metodológicos generales de las investigaciones revisadas, encontrándose presente en el 68\% de los artículos de liderazgo educativo del período. Le sigue la encuesta, que forma parte del diseño general del $41 \%$ de los estudios. Cabe señalar que un $15 \%$ de las investigaciones combina ambos tipos de diseño. Llama la atención que, teniendo Chile una batería amplia y de reconocida calidad de datos provenientes de pruebas nacionales (Simce) e internacionales (PISA, TALIS, TERCE) que suelen incorporar información acerca del liderazgo, el análisis de datos secundarios sea el diseño general de solo tres artículos.

Respecto del muestreo, solo se desarrollan muestreos aleatorios en un $23 \%$ de los artículos, lo que repercute en que un grupo muy reducido de las investigaciones (11 artículos) permiten extraer conclusiones en torno al liderazgo educativo en Chile con ciertos

16 Si entre 2008 y 2015 solo el 8\% de los artículos era mixto, entre 2016 y 2019 el 32\% correspondía a este tipo de estudio; en cambio los artículos cualitativos han disminuido de un $54 \%$ a un $35 \%$ en iguales períodos. 
niveles de representatividad. Con todo, se observa un incremento en las investigaciones que cuentan con muestreos aleatorios durante los últimos años ${ }^{17}$.

En cuanto a las técnicas de producción de información, destaca el claro predominio de las entrevistas y los cuestionarios, siendo aplicadas en el 55\% y en el 53\% de los artículos, respectivamente. La información generada mediante estas técnicas es complementada por espacios grupales y observaciones, en los estudios cualitativos y mixtos, y por el uso de datos secundarios, en los tres tipos de estudios.

Pese a la preponderancia que alcanzan las entrevistas y los cuestionarios, se observa cierta tendencia hacia una mayor diversificación de técnicas entre los períodos 2008-2015 y 20162019. En particular, entre los estudios cualitativos y mixtos aumenta el número de técnicas desarrolladas por las investigaciones ${ }^{18}$, en tanto, los estudios cuantitativos han comenzado a utilizar datos secundarios para producir información ${ }^{19}$.

En cuanto a los tipos de análisis, sobresale el desarrollo de análisis cualitativo de discursos en el 66\% de los estudios, correspondientes a investigaciones cualitativas y mixtas. Si bien originariamente se buscó diferenciar entre tipos de análisis cualitativos, ello no resultó posible debido a la poca especificidad con que se describían los análisis efectuados en los artículos. Por otra parte, se observa que tanto la estadística descriptiva como la estadística correlacional y multivariada se desarrollan como tipos de análisis en una similar proporción de investigaciones, alcanzando el $45 \%$ y el $38 \%$ de los estudios respectivamente. Cabe señalar que se observa un incremento progresivo en el desarrollo de análisis estadísticos correlacionales y multivariados, en detrimento de la estadística descriptiva durante el período revisado ${ }^{20}$.

17 Si en el período 2008-2015 las investigaciones con muestreos aleatorios solo correspondían al 15\% del total de artículos, en el período 2016-2019 estas ascienden al 26\%.

18 El número de investigaciones que usa tres o más técnicas asciende del $12 \%$ al $31 \%$ en los períodos señalados.

19 La utilización de datos secundarios pasa del 0\% al 25\% en los períodos señalados.

20 En el período 2008-2015 en un 50\% de los estudios cuantitativos y mixtos se efectuaban análisis estadísticos correlacionales y multivariados; en tanto, en el período 2016-2019, dicho porcentaje ascendió al 68\%. 
Tabla 5

Diseño metodológico según tipo de estudio

\begin{tabular}{|c|c|c|c|}
\hline & $\begin{array}{c}\text { Cualitativos } \\
\text { (19) }\end{array}$ & $\begin{array}{c}\text { Cuantitativos } \\
(16)\end{array}$ & $\begin{array}{c}\text { Mixtos } \\
(12) \\
\end{array}$ \\
\hline $\begin{array}{l}\text { Diseño } \\
\text { general }\end{array}$ & $\begin{array}{l}\text { - Estudio de caso: } 100 \% \\
\text { (19). }\end{array}$ & $\begin{array}{l}\text { - Encuesta: } 75 \%(12) \text {. } \\
\text { - Análisis de datos } \\
\text { secundarios: } 19 \%(3) \text {. } \\
\text { - Estudio de caso: } 6 \%(1) \text {. }\end{array}$ & $\begin{array}{l}\text { - Estudios de caso: } 42 \% \\
\text { ( } 5 \text { ). } \\
\text { - Estudios de caso + } \\
\text { Encuesta: } 58 \%(7) \text {. }\end{array}$ \\
\hline Muestreo & $\begin{array}{l}\text { - No aleatorio: } 100 \% \text { (19). } \\
\text { - Ocho casos promedio. }\end{array}$ & $\begin{array}{l}\text { - Aleatorio: } 56 \%(9) \\
\text { - No aleatorio: } 25 \%(4) \\
\text { - No reportado: } 19 \% \text { (3). }\end{array}$ & $\begin{array}{l}\text { - Aleatorio: } 17 \%(2) \text {. } \\
\text { - No aleatorio: } 67 \%(8) \text {. } \\
\text { - No reportado: } 17 \%(2) \text {. } \\
9,5 \text { casos promedio. }\end{array}$ \\
\hline Técnicas & $\begin{array}{l}\text { - Entrevistas: } 84 \% \text { (16). } \\
\text { - Espacios grupales: } 47 \% \\
\text { ( } 9 \text { ). } \\
\text { - Observación: } 26 \% \text { (5). } \\
\text { - U s o de d a t o s } \\
\text { secundarios: } 16 \% \text { (3). }\end{array}$ & $\begin{array}{l}\text { - Cuestionarios: } 81 \% \\
\text { (13). } \\
\text { - Uso de datos } \\
\text { secundarios: } 25 \% \text { (4). }\end{array}$ & $\begin{array}{l}\text { - Cuestionario: } 100 \% \\
\text { (12). } \\
\text { - Entrevista: } 80 \% \text { (10). } \\
\text { - Espacios grupales: } 50 \% \\
\text { (6). } \\
\text { - Observación: } 25 \% \text { (3). } \\
\text { - U s o d e d a to s } \\
\text { secundarios: } 8 \%(1) \text {. }\end{array}$ \\
\hline Análisis & $\begin{array}{l}\text { - Cualitativo de discursos: } \\
100 \% \text { (19). }\end{array}$ & $\begin{array}{l}\text { - Estadística descriptiva: • } \\
\text { 31\% (5). } \\
\text { - Estadística correlacional } \\
\text { - E multivariada: } 13 \%(2) \text {. } \\
\text { Estadística descriptiva + • } \\
\text { Estadística correlacional } \\
\text { y multivariada: } 56 \%(9) \text {. }\end{array}$ & $\begin{array}{l}\text { - Cualitativo de discursos: } \\
100 \%(12) \text {. } \\
\text { - Estadística descriptiva: } \\
42 \%(5) \text {. } \\
\text { - Estadística correlacional } \\
\text { y multivariada: } 42 \%(5) \text {. } \\
\text { - Estadística descriptiva + } \\
\text { Estadística correlacional } \\
\text { y multivariada: } 16 \% \text { (2). }\end{array}$ \\
\hline
\end{tabular}

Fuente: Elaboración propia.

Al indagar en el diseño metodológico según tipo de estudio realizado se observan algunas particularidades relevantes. En los estudios cualitativos destaca que la totalidad corresponde a estudios de caso, aunque se observa una amplia variedad respecto del número de casos estudiados — situándose las investigaciones entre el estudio de solo un caso hasta 25 casos-. En los estudios cuantitativos destaca el predominio de la encuesta (75\%) frente a una mucha menor proporción de análisis de datos secundarios (19\%). Por último, entre los estudios mixtos se pueden diferenciar entre las investigaciones cuyo diseño general corresponde solo a estudios de caso $(42 \%)^{21}$ y aquellas que combinan estudios de caso y encuesta $(58 \%)^{22}$.

21 Investigaciones en las que a continuación de la fase cualitativa se aplica un cuestionario a actores de las mismas escuelas que participaron de dicha primera fase.

22 Investigaciones en las que que la unidad muestral cambia entre ambas fases, efectuándose cuestionarios a una muestra distinta de la de la fase cualitativa. 
A nivel del muestreo se pueden observar dos diferencias relevantes según el tipo de estudio. En primer lugar, los estudios cuantitativos tienden a poseer mayor aleatoriedad (56\%) que los estudios mixtos (17\%). En segundo lugar, los estudios mixtos poseen un número promedio de casos ligeramente mayor $(9,5)$ que los estudios cualitativos (8).

Respecto de las técnicas, si bien las entrevistas, espacios grupales y observaciones en estudios cualitativos y mixtos se desarrollan en una proporción similar, destaca un mayor uso de datos secundarios en estudios cualitativos y la relevancia que adquieren los cuestionarios en el caso de las investigaciones mixtas, los que se encuentran asociados a su componente cuantitativo. En el caso de los estudios cuantitativos, destaca la preeminencia de los cuestionarios frente al uso de datos secundarios. Cabe señalar que solo en un artículo se combinan ambas técnicas, lo que confirma lo circunscrita que se encuentra la utilización de datos secundarios.

Finalmente, en cuanto a los tipos de análisis, tanto en los estudios cualitativos como en los mixtos la totalidad de investigaciones desarrolla análisis cualitativos de discursos, frecuentemente consistentes en sucesivas fases de codificación y categorización. En tanto, se observa una mayor utilización combinada de los análisis estadísticos descriptivos y de los análisis estadísticos correlacionales y multivariados en las investigaciones cuantitativas que en las mixtas ${ }^{23}$.

\section{4. ¿Dónde se publica?}

Del total de artículos publicados hay una distribución mayoritaria en idioma español, pero con una minoría relevante, algo mayor a un tercio, de publicaciones en inglés. Más precisamente, hay un 64\% del total de artículos en español y un 36\% en inglés. La publicación en uno u otro idioma está asociada con el tipo de estudio realizado, teniendo una mayor publicación en inglés los estudios con metodologías mixtas (42\%), seguidos por aquellos con metodologías

23 Mientras en las investigaciones cuantitativas la combinación de ambos tipos de análisis alcanza al 56\% de los artículos, en las investigaciones mixtas ambos tipos de análisis solo se efectúan conjuntamente en el $16 \%$. 
cuantitativas (37\%), ambos por sobre aquellos que refieren a estudios cualitativos (31\%).

Las publicaciones se distribuyen en una variedad amplia de revistas. Las revistas que tienen más de dos artículos publicados en el período, pero ninguna más de cuatro, son solo cuatro: Calidad de la Educación (4); Educational Management Administration and Leadership (4); Estudios Pedagógicos (3); y REICE (3). En términos del tipo de revistas indexadas que publican los artículos sobre liderazgo educativo en Chile, los resultados muestran que la mayoría se publica en revistas generales de educación (53\%), mientras que una minoría lo hace en revistas especializadas en liderazgo y gestión escolar (26\%), existiendo también un grupo minoritario de publicaciones (21\%) en otras revistas indexadas que no pertenecen al campo educativo (por ejemplo, administración). Es interesante constatar que, como muestra el cuadro que sigue, las revistas que publican esta producción académica sobre el liderazgo educativo chileno están concentradas en ciertos países como Chile, Reino Unido, o España, no existiendo ningún artículo publicado en una revista de Estados Unidos durante la década estudiada. Desde otro ángulo, puede apreciarse que las revistas editadas en países de América Latina han publicado el 57\% del total los artículos.

Tabla 6

Países de las revistas en las que fueron publicados los artículos

\begin{tabular}{lcc}
\hline País & $\%$ & $\mathrm{~N}^{\circ}$ \\
\hline Chile & $26 \%$ & 12 \\
\hline Reino Unido & $26 \%$ & 12 \\
\hline España & $11 \%$ & 5 \\
\hline Colombia & $9 \%$ & 4 \\
\hline Venezuela & $9 \%$ & 4 \\
\hline Brasil & $6 \%$ & 3 \\
\hline México & $6 \%$ & 3 \\
\hline Holanda & $4 \%$ & 2 \\
\hline Argentina & $2 \%$ & 1 \\
\hline Corea del Sur & $2 \%$ & 1
\end{tabular}

Fuente: Elaboración propia. 
Desde el punto de vista de la indexación de las revistas, hay un predominio de aquellas indexadas en Scopus, mientras que aquellas en las que menos se ha publicado corresponden a WoS. La Figura 7 permite visualizar los porcentajes de artículos que han sido publicados bajo cada una de las indexaciones consideradas ${ }^{24}$ :

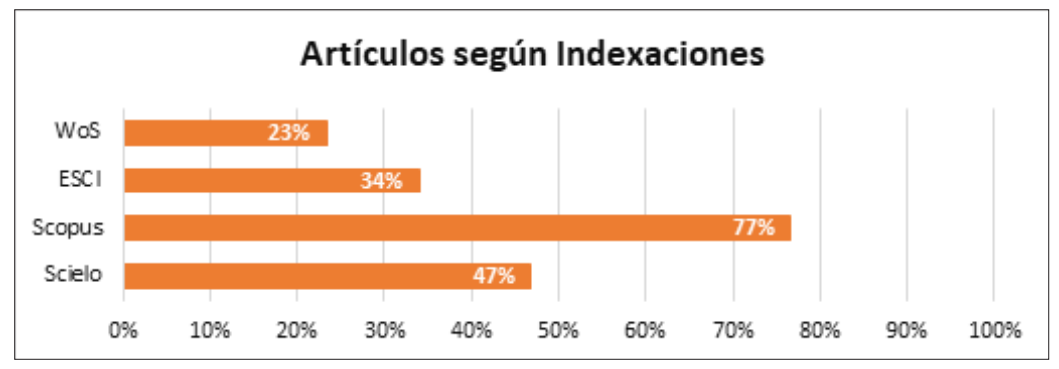

Figura 7. Artículos según indexaciones

Fuente: Elaboración propia.

Conviene hacer tres precisiones adicionales respecto de este resultado. La primera es que la cantidad de artículos publicados en las revistas indexadas en ESCI-WoS ha aumentado fuertemente en el último período, convirtiéndose en un espacio de publicación significativo para los autores chilenos. Así, si las revistas bajo esta indexación correspondían solo al 15\% en el período 2008-2015, este porcentaje casi se triplicó, aumentando al 41\% en el período 2016$2019^{25}$. La segunda es que la metodología que utilizan los estudios de los artículos está asociada a la indexación que tienen las revistas que los publican. De este modo, las revistas WoS suelen publicar más estudios mixtos que el resto (estos estudios corresponden al $45 \%$ del total de artículos que han publicado), mientras que aquellas indexadas como ESCI-WoS han publicado más estudios cualitativos (63\% de sus artículos corresponden a esta metodología). La tercera, es que las investigaciones que han contado con financiamiento han alcanzado un nivel mayor de indexación que aquellas que no declaran haberlo tenido. En particular, de los artículos publicados en las revistas WoS, un 77\% contó con alguna fuente declarada de

24 Dado que algunas revistas están consideradas en varias indexaciones, la suma de los porcentajes no corresponde a $100 \%$.

25 En este resultado debe considerarse que se trata de una indexación reciente y que no cubre todo el período inicial. 
financiamiento, en comparación con solo un 38\% de los publicados en revistas SciELO.

En relación con los dos centros de liderazgo educativo, CEDLE y Líderes Educativos, que ha apoyado el Mineduc desde el año 2016, puede apreciarse que, desde ese año a la fecha, han participado en la autoría del 38\% de los artículos publicados. Sus publicaciones destacan respecto del resto por el mayor porcentaje de artículos que han sido aceptados en revistas de idioma inglés — los artículos en inglés de los centros suman el $54 \%$ de sus publicaciones versus un 29\% del resto de los artículos-, en particular en revistas del Reino Unido.

\section{Discusión y conclusiones}

Esta revisión topográfica ha analizado de manera sistemática los artículos acerca de liderazgo educativo en Chile que cuentan con una base de investigación empírica y que se han publicado en revistas indexadas en la última década.

Sus principales resultados pueden sintetizarse del siguiente modo:

- El total de artículos publicados es de 47, con una tendencia a incrementarse sustantivamente desde el año 2016 en adelante.

- Son 85 los autores y autoras de los artículos, hay cierta presencia masculina mayoritaria y poseen habitualmente estudios de posgrado (mayoría con doctorado).

- Un 75\% de los autores ha escrito un solo artículo, siendo pequeño el grupo que ha escrito más de tres artículos acerca de la temática.

- La mayoría de los artículos ha sido escrito por académicos afiliados a universidades privadas del CRUCH, existiendo dos instituciones (UCV y UDP) que concentran la mitad de las publicaciones.

- Hay una baja participación de autores afiliados a universidades extranjeras, y cuando publican artículos lo hacen en coautoría con académicos afiliados a instituciones chilenas.

- El 40\% de los estudios publicados no declara haber recibido algún tipo de financiamiento para su realización. 
- Un 62\% de los artículos corresponde a estudios descriptivos, habitualmente acerca de prácticas de liderazgo, siendo minoritarios los que intentan establecer algún tipo de relación causal entre los antecedentes y las prácticas, o bien, entre prácticas y sus efectos en estudiantes, docentes o en el establecimiento escolar en su conjunto.

- Las cinco dimensiones de prácticas descritas por el Marco para la buena dirección (Mineduc, 2015) cuentan con artículos que buscan estudiarlas, siendo algunas más investigadas que otras.

- Kenneth Leithwood es el autor de referencia sobre liderazgo más citado (lo hacen 79\% de los artículos), seguido por Alma Harris y Vivianne Robinson.

- La mitad de los artículos no define su marco conceptual en términos de seguir un enfoque específico de liderazgo educativo. En la mitad que sí lo hace, predominan el liderazgo instruccional, transformacional y distribuido (en ese orden).

- Los directores y directoras han sido el actor más estudiado en cuanto a su liderazgo, siendo el foco investigativo en un $81 \%$ de los artículos. En términos de actores informantes, luego de los propios directores, destaca la presencia de los docentes (en la mitad de las publicaciones).

- Los establecimientos escolares más estudiados han sido las escuelas básicas, así como los establecimientos de dependencia municipal (91\% de los artículos refiere a ellos, sea en exclusiva o en combinación con otra dependencia).

- Los artículos provienen de investigaciones que han empleado, en orden de importancia, metodologías cualitativas, cuantitativas y mixtas.

- Ha existido un predominio de los estudios de caso por sobre otro tipo de estudios, con una baja cantidad de investigaciones cuantitativas que hayan desarrollado procedimientos de muestreo aleatorio de sus encuestados y con un escaso uso de los datos secundarios como base de la indagación.

- Un 64\% de los artículos se ha publicado en español y un 36\% en inglés.

- Las revistas en las que se publican los artículos son mayoritariamente de investigación educativa en general, seguidas por revistas 
especializadas en temáticas de liderazgo y gestión escolar. Estas revistas son publicadas principalmente en Latinoamérica (y en Europa se trataría de revistas especialmente inglesas y españolas), y tienen en su mayoría una indexación Scopus (siendo WoS la indexación menos frecuente).

Al analizar estos resultados es importante señalar que esta revisión topográfica tiene limitaciones en términos de la información que ha sido considerada. El foco exclusivo puesto en los artículos publicados en revistas indexadas ha dejado fuera libros y capítulos de libros, tesis de pregrado y posgrado, revistas no indexadas, y documentos de la llamada literatura gris (como los documentos de política publicados por instituciones gubernamentales o los informes técnicos derivados de los proyectos de investigación). Futuras revisiones sistemáticas debieran considerar también estas fuentes, así como las publicaciones que no tienen una base empírica, para tener una visión completa de la producción académica existente en Chile en cuanto a esta temática.

Con todo, la caracterización resultante se corresponde con la noción de que el estudio del liderazgo educativo en Chile es un campo emergente de investigación (Hallinger, 2019; Oplatka, 2018). En efecto, al mismo tiempo que tiene un escaso desarrollo como campo especializado de investigación, presentando debilidades y desafíos múltiples en términos de la producción científica que se ha llevado a cabo, es un campo que está en pleno desarrollo, y cuyos resultados reflejan una tendencia reciente, desde el año 2016 en adelante, a una significativamente mayor labor de investigación.

Pero para continuar su consolidación como campo de investigación no basta con que se multipliquen los estudios y las consiguientes publicaciones en revistas indexadas. Se requiere también avanzar en cuanto a cubrir la complejidad y diversidad del fenómeno del liderazgo educativo en los establecimientos escolares de Chile que, como ha mostrado esta revisión topográfica, no está siendo mapeado de manera completa. En este sentido es crucial que se avance hacia el estudio del liderazgo no solo de los directores y directoras, sino que también del que llevan a cabo los equipos 
directivos y también los docentes al interior de los establecimientos. Igualmente, se requiere estudiar la realidad del liderazgo más allá de los establecimientos municipales, analizando qué es lo que acontece en los establecimientos privados - en particular en los privados subvencionados que concentran la mayoría de la matrícula escolar, siendo el anhelo educativo prioritario de las clases medias (Canales, Bellei y Orellana, 2016) — . Del mismo modo, es necesario expandirse más allá de las escuelas básicas, y conocer en profundidad lo que acontece en los liceos de la enseñanza media, el nivel que ha sido calificado como el de mayor complejidad para la mejora escolar dentro de nuestro sistema educativo (Bellei, 2012).

Pero junto con ampliar la investigación acerca del liderazgo educativo hacia otros actores y establecimientos escolares que han sido poco estudiados, se debe avanzar en los alcances y tipos de investigación que se ha tendido a desarrollar. Se trata no solo de ampliar la indagación hacia objetos de estudio poco abordados, sino que también de profundizarla (Gumus, Beliban, Essen \& Gumus, 2018). Así, un campo de estudio consolidado debe ir más allá de la descripciones de las prácticas que efectúan los directivos escolares, para buscar realizar estudios que busquen relacionar dichas prácticas de liderazgo con los antecedentes individuales o de contexto en los que estas se llevan a cabo (Hallinger, 2011). Igualmente debe avanzar hacia establecer los eventuales efectos que ha provocado el liderazgo educativo en términos de transformaciones en los docentes, en los estudiantes o en el establecimiento escolar en su conjunto (Leithwood, Day, Sammons, Harris \& Hopkins, 2006). Este cambio sugerido en los tipos de investigación, pasando desde una investigación principalmente descriptiva hacia una con preponderancia relacional y causal, tiene también un correlato en materia de las metodologías de estudio requeridas. De esta forma, se necesita avanzar hacia una mayor sofisticación metodológica, en la que se empleen técnicas de investigación, tanto cuantitativas como cualitativas, más complejas y variadas que las que suelen utilizarse mayoritariamente en la actualidad. En la misma dirección, es relevante impulsar más estudios que se basen en muestreos aleatorios de los actores y establecimientos estudiados, cuyos resultados puedan ser generalizados a poblaciones más amplias, así como también deben explotarse las abundantes 
bases de datos secundarios disponibles derivadas de las mediciones nacionales e internacionales.

Para hacer este paso desde un campo emergente hacia un campo consolidado de investigación se requerirá de condiciones de base e institucionales que lo posibiliten. Contar con un grupo mayor de investigadores e investigadoras especializados en la temática; consolidar varios núcleos académicos dedicados en diferentes universidades y centros de estudio (especialmente entre las instituciones que hacen formación de posgrado sobre liderazgo educativo); obtener un financiamiento adecuado y constante para desarrollar investigación; o avanzar hacia relaciones de cooperación académica de mediano y largo plazo con académicos de universidades extranjeras dedicados al tema, están entre las condiciones requeridas para ir generando la base de conocimiento necesaria para informar, de manera contextualizada, las políticas y las prácticas de liderazgo educativo.

Finalmente, conviene recordar que este despertar de la investigación de liderazgo educativo en Chile se enmarca en un fenómeno global, compartido por diferentes sociedades y sistemas educativos. Como dicen Hammad y Hallinger (2017), "por primera vez una masa crítica de investigadores ha comenzado a estudiar la diversidad de las prácticas de liderazgo y gestión escolar más allá de los tradicionales centros de estudio angloamericanos" (p. 435). Así, al mismo tiempo que en Chile, empiezan a desarrollarse investigaciones en China (Walker, Hu \& Qian, 2012), en las sociedades árabes (Hammad \& Hallinger, 2017), en los países africanos (Hallinger, 2018) o en el sudeste asiático (Hallinger \& Bryant, 2013).

Esta emergente investigación tiene que enfrentar el difícil desafío de leer adecuadamente el contexto socioeducativo y cultural que le es propio, sin desechar todo lo acumulado por la investigación anglosajona durante décadas. Se trata de distinguir lo universal que puede encontrarse en dichas teorías de liderazgo y la gestión educativa de lo idiosincrático (Bush, 2018), pero también de crear las categorías y conceptos pertinentes para dar cuenta de una realidad socioeducativa y cultural particular (Oplatka, 2018). Las eventuales 
distorsiones de una importación irreflexiva pueden no solo ser perjudiciales para la investigación, sino que también pueden tener consecuencias indeseadas para las políticas destinadas a fomentar el liderazgo educativo, dado que justamente una de las funciones de la investigación es informar adecuadamente a las políticas para diseñar e implementar planes de acción pertinentes y contextualizados a cada sistema escolar.

\section{Referencias}

Aravena F. \& Hallinger, P. (2018). Systematic review of research on educational leadership and management in Latin America, 1991-2017. Educational Management Administration E Leadership, 46(2), 207-225. https://doi.org/10.1177/1741143217745882

Bellei, C. (2012). Políticas educativas para el nivel secundario: complejidades y convergencias. En E. Tenti (Coord.), La escolarización de los adolescentes: desafíos culturales, pedagógicos y de política educativa (pp. 209-253). Buenos Aires: IIPE/Unesco.

Bush, T. (2016). Mejora escolar y modelos de liderazgo: hacia la comprensión de un liderazgo efectivo. En J. Weinstein (Ed.), Liderazgo educativo en la escuela. Nueve miradas (pp. 19-44). Santiago de Chile: Ediciones UDP.

Bush, T. (2018). Research on educational leadership and management: Broadening the base. Educational Management Administration \& Leadership, 46(3), 359-361. https://doi. org/10.1177/1741143218758555

Canales, M., Bellei, C. y Orellana, V. (2016). ¿Por qué elegir una escuela privada subvencionada? Sectores medios emergentes y elección de escuela en un sistema de mercado. Estudios Pedagógicos (Valdivia), 42(3), 89-109. http://dx.doi.org/10.4067/S0718-07052016000400005

Centro de Desarrollo de Liderazgo Educativo, CEDLE (2016). Sistema educacional chileno: ¿qué políticas para los directivos? (Cuaderno técnico $\left.n^{\circ} 1\right)$. Santiago de Chile: Autor.

Flessa, J., Bramwell, D., Fernández, M., \& Weinstein, J. (2018). School leadership in Latin America 2000-2016. Educational Management Administration \& Leadership, 46(2), 182-206. https://doi. org/10.1177/1741143217717277

Gough, D., Oliver, S., \& Thomas, J. (Eds.). (2017). An introduction to systematic reviews. London: Sage. 
Gumus, S., Bellibas, M. S., Esen, M., \& Gumus, E. (2018). A systematic review of studies on leadership models in educational research from 1980 to 2014. Educational Management Administration \& Leadership, 46(1), 25-48. https://doi.org/10.1177/1741143216659296

Hallinger, P. (2011). Leadership for learning: Lessons from 40 years of empirical research. Journal of Educational Administration, 49(2), 125142. https://doi.org/10.1108/09578231111116699

Hallinger, P. (2013). A conceptual framework for systematic reviews of research in educational leadership and management. Journal of Educational Administration, 51(2), 126-149. https://doi. org/10.1108/09578231311304670

Hallinger, P. (2014). Reviewing reviews of research in educational leadership: An empirical assessment. Educational Administration Quarterly, 50(4), 539-576. https://doi.org/10.1177/0013161X13506594

Hallinger, P. (2018). Surfacing a hidden literature: A systematic review of research on educational leadership and management in Africa. Educational Management Administration \& Leadership, 46(3), 362-384. https://doi.org/10.1177/1741143217694895

Hallinger, P. (2019). Science mapping the knowledge base on educational leadership and management from the emerging regions of Asia, Africa and Latin America. 1965-2018. Educational Management Administration and Leadership, 1-22. https://doi.org/10.1177/1741143218822772

Hallinger, P. \& Bryant, D. (2013). Mapping the terrain of educational leadership and management in East Asia. Journal of Educational Administration, 51(5), 618-637. https://doi.org/10.1108/JEA-05-20120066

Hammad, W. \& Hallinger, P. (2017). A systematic review of conceptual models and methods used in research on educational leadership and management in Arab societies. School Leadership \& Management, 37(5), 434-456. https://doi.org/10.1080/13632434.2017.1366441

Hernández Sampieri, R., Fernández Collado, C., y Baptista Lucio, P. (2010). Metodología de la investigación (Vol. 3). México, DF: McGraw-Hill.

IBM Corp. Released 2016. IBM SPSS Statistics for Windows, Version 24.0. Armonk, NY: IBM Corp.

Leithwood, K., Day, C., Sammons, P., Harris, A., \& Hopkins, D. (2006). Successful school leadership. What it is and how it influences pupil learning. Report. Reading: CfBT Education Trust. Recuperado de https:// www.researchgate.net/publication/238717790_Successful_School_ Leadership_What_It_Is_and_How_It_Influences_Pupil_Learning 
Ministerio de Educación, Mineduc (2015). Marco para la Buena Dirección y el Liderazgo Escolar. Santiago de Chile: Autor.

Moher, D., Liberati, A., Tetzlaff, J., \& Altman, D. G. (2009). Preferred reporting items for systematic reviews and meta-analyses: The PRISMA statement. Annals of Internal Medicine, 151(4), 264-269. https://doi. org/10.1371/journal.pmed.1000097

Muñoz, G., Amenábar, J., y Valdebenito, M. J. (2019). Formación de directivos escolares en Chile: situación actual, evolución y desafíos de su oferta. REICE. Revista Iberoamericana sobre Calidad, Eficacia y Cambio en Educación, 17(2). https://doi.org/10.15366/reice2019.17.2.003

Murillo, F. (2012). La dirección escolar en Chile: una visión en el contexto de América Latina. En J. Weinstein y G. Muñoz (Eds.), ¿Qué sabemos sobre los directores de escuela en Chile? (pp. 19-40). Santiago de Chile: Fundación Chile y CEPPE-UC.

Núñez, I., Weinstein, J., y Muñoz, G. (2010). ¿Posición olvidada? Una mirada desde la normativa a la historia de la dirección escolar en Chile. Psicoperspectivas, 9(2), 53-81. http://dx.doi.org/10.5027/ psicoperspectivas-Vol9-Issue2-fulltext-117

Organización de las Naciones Unidas para la Educación, la Ciencia y la Cultura, Unesco (2014). El liderazgo escolar en América Latina y el Caribe. Un estado del arte en base a ocho sistemas escolares de la región. Santiago de Chile: OREALC/Unesco.

Organización para la Cooperación y el Desarrollo Económicos, OCDE. (2017). Revisión de políticas nacionales en educación: Chile. París: Autor.

Oplatka, I. (2018). Educational administration and the relational approach: Can we suffice contextual-based knowledge production? En S. Eacott (Ed.), Beyond leadership (pp. 199-210). Singapur: Springer. https://doi. org/10.1007/978-981-10-6568-2_12

Walker, A., Hu, R., \& Qian, H. (2012). Principal leadership in China: An initial review. School Effectiveness and School Improvement, 23(4), 369399. https://doi.org/10.1080/09243453.2012.678863

Weinstein, J. y Hernández Vejar, M. (2014). Políticas hacia el liderazgo directivo escolar en Chile: Una mirada comparada con otros sistemas escolares de América Latina. Psicoperspectivas, 13(3), 52-68. http:// dx.doi.org/10.5027/psicoperspectivas-Vol13-Issue3-fulltext-468

Recibido: 14/06/2019

Aceptado: 06/09/2019 


\section{Anexo 1}

\section{Listado de artículos seleccionados}

\begin{tabular}{|c|c|c|c|}
\hline Nombre del artículo & Autor(es) & Año & Revista \\
\hline $\begin{array}{l}\text { Estilos de liderazgo y resultados } \\
\text { del sistema de medición de la } \\
\text { calidad de la educación: un estudio } \\
\text { empírico en los colegios básicos de } \\
\text { la ciudad de Arica-Chile }\end{array}$ & $\begin{array}{l}\text { Liliana Pedraja; } \\
\text { Emilio Rodríguez; } \\
\text { Manuel Barreda; } \\
\text { Omar Sagredo; } \\
\text { Cristian Segovia }\end{array}$ & 2009 & $\begin{array}{l}\text { Ingeniare. Revista } \\
\text { Chilena de } \\
\text { Ingeniería }\end{array}$ \\
\hline $\begin{array}{l}\text { El funcionamiento del equipo } \\
\text { directivo durante un proceso de } \\
\text { autoevaluación institucional en el } \\
\text { marco de políticas de aseguramiento } \\
\text { de la calidad de la gestión escolar en } \\
\text { Chile }\end{array}$ & $\begin{array}{l}\text { Luis Ahumada; } \\
\text { Sergio Galdames; } \\
\text { Álvaro González; } \\
\text { Paula Herrera }\end{array}$ & 2010 & $\begin{array}{l}\text { Universitas } \\
\text { Psychologica }\end{array}$ \\
\hline $\begin{array}{l}\text { El componente liderazgo en la } \\
\text { validación de un modelo de gestión } \\
\text { escolar hacia la calidad }\end{array}$ & Pablo López & 2010 & $\begin{array}{l}\text { Educação } \\
\text { Pesquisa }\end{array}$ \\
\hline $\begin{array}{l}\text { Liderazgo distribuido durante } \\
\text { el proceso de elaboración e } \\
\text { implementación de planes de } \\
\text { mejoramiento educativo en una } \\
\text { comuna rural en Chile }\end{array}$ & $\begin{array}{l}\text { Luis Ahumada; } \\
\text { Vicente Sisto; } \\
\text { Verónica López; } \\
\text { Juan Pablo } \\
\text { Valenzuela }\end{array}$ & 2011 & $\begin{array}{l}\text { Revista de Ciencias } \\
\text { Sociales (Ve) }\end{array}$ \\
\hline $\begin{array}{l}\text { Liderazgo de los directivos docentes } \\
\text { en contextos vulnerables }\end{array}$ & $\begin{array}{l}\text { Carmen Tapia; } \\
\text { Sandra Becerra; } \\
\text { Juan Mancilla; July } \\
\text { Saavedra }\end{array}$ & 2011 & $\begin{array}{l}\text { Educación y } \\
\text { Educadores }\end{array}$ \\
\hline $\begin{array}{l}\text { School principals at their lonely } \\
\text { work: Recording workday practices } \\
\text { through ESM logs }\end{array}$ & $\begin{array}{l}\text { Verónica López; } \\
\text { Luis Ahumada; } \\
\text { Sergio Galdames; } \\
\text { Romina Madrid }\end{array}$ & 2012 & $\begin{array}{l}\text { Computers } \varepsilon \\
\text { Education }\end{array}$ \\
\hline $\begin{array}{l}\text { Problemas de gestión asociados al } \\
\text { liderazgo como función directiva }\end{array}$ & $\begin{array}{l}\text { Jorge Ulloa; Oscar } \\
\text { Nail; Abelardo } \\
\text { Castro; Máximo } \\
\text { Muñoz }\end{array}$ & 2012 & $\begin{array}{l}\text { E s t u d i o s } \\
\text { Pedagógicos }\end{array}$ \\
\hline $\begin{array}{l}\text { Ethical practice: A study of Chilean } \\
\text { school leaders }\end{array}$ & $\begin{array}{l}\text { Carolina Cuellar; } \\
\text { David Giles }\end{array}$ & 2012 & $\begin{array}{l}\text { Journal of } \\
\text { Educational } \\
\text { Administration }\end{array}$ \\
\hline $\begin{array}{l}\text { School violence: subjective theories } \\
\text { of academic advisory board } \\
\text { members from six Chilean schools }\end{array}$ & $\begin{array}{l}\text { Gabriella Von } \\
\text { Reininghaus; Pablo } \\
\text { Castro; Susana } \\
\text { Frisancho }\end{array}$ & 2013 & Interdisciplinaria \\
\hline
\end{tabular}


When duties are not enough: José Weinstein; 2014 School Effectiveness Principal leadership and public or Gonzalo Muñoz and School private school management in Chile Improvement: An International Journal of Research, Policy and Practice

Factores que dificultan la gestión Juan Carlos Beltrán 2014 Revista Mexicana pedagógica curricular de los jefes de Unidades Técnico Pedagógicas de Investigación Educativa

Satisfacción laboral y estilos de liderazgo en instituciones públicas y privadas de educación en Chile

María Chiang;

Nelly Gómez; Carlos Salazar

Understanding leadership in schools Luis Ahumada; facing challenging circumstances: A Sergio Galdames; Chilean case study Simon Clarke
2014 Cuadernos de Administración

2015 International Journal of Leadership in Education

Instructional leadership among novice principals in Chile: Practices for classroom observation and feedback to teachers

María Verónica Leiva; Carmen Montecinos; Felipe Aravena

Liliana Pedraja; E m i l i a n o Rodríguez; Patricio Rodríguez escolar y el logro académico de los estudiantes: un estudio exploratorio

La relación entre el estilo de Liliana Pedraja; liderazgo del director y la Emilio Rodríguez;

2016 Revista Electrónica de Investigación y Evaluación Educativa

2016 Interciencia

$2016 \begin{aligned} & \text { Revista de } \\ & \text { Pedagogía }\end{aligned}$
satisfacción de los estudiantes: evidencia desde Chile

Carmen Araneda; Patricio Rodríguez

Liderazgo transformacional y su Francisco Ganga; incidencia en la gestión docente: el Francisco Villegas; caso de un colegio en el norte de Liliana Pedraja; chile Emilio Rodríguez

\begin{tabular}{|c|c|c|c|}
\hline $\begin{array}{l}\text { Director(a) por primera vez. Un } \\
\text { estudio sobre la experiencia y } \\
\text { socialización de los directores } \\
\text { noveles en establecimientos } \\
\text { municipales de Chile }\end{array}$ & $\begin{array}{l}\text { José Weinstein, } \\
\text { Carolina Cuéllar, } \\
\mathrm{M} \text { a c a } \mathrm{r} \text { n a } \\
\mathrm{H} \text { e r n án de z, } \\
\mathrm{M} \text { a g d a l e n a } \\
\text { Fernández }\end{array}$ & 2016 & $\begin{array}{l}\text { Calidad en la } \\
\text { Educación }\end{array}$ \\
\hline $\begin{array}{l}\text { The relationship between leadership } \\
\text { preparation and the level of } \\
\text { teachers' interest in assuming a } \\
\text { principalship in Chile }\end{array}$ & $\begin{array}{l}\text { Sergio Galdames; } \\
\text { Álvaro González }\end{array}$ & 2016 & $\begin{array}{l}\text { School Leadership } \\
\text { \& Management }\end{array}$ \\
\hline
\end{tabular}

2016 Interciencia 
El papel directivo y la promoción de la participación de las familias y la comunidad en las escuelas básicas. El caso de la comuna de Panguipulli-Chile

\begin{tabular}{|c|c|c|c|}
\hline $\begin{array}{l}\text { How local market pressures shape } \\
\text { leadership practices: Evidence from } \\
\text { Chile }\end{array}$ & $\begin{array}{l}\text { A } 1 \text { e j a n d r o } \\
\text { Carrasco; German } \\
\text { Fromm }\end{array}$ & 2016 & $\begin{array}{l}\text { Journal of } \\
\text { Education al } \\
\text { Administration and } \\
\text { History }\end{array}$ \\
\hline $\begin{array}{l}\text { Liderazgo escolar en tiempos de } \\
\text { crisis. El caso de dos liceos del } \\
\text { centro sur de Chile después del } 27 \mathrm{~F}\end{array}$ & $\begin{array}{l}\text { Javier Pascual; } \\
\text { Denis Larraguibel; } \\
\text { Daniela Zenteno; } \\
\text { Francisca Guarda }\end{array}$ & 2016 & REICE \\
\hline $\begin{array}{l}\text { Incidencia de la dirección escolar } \\
\text { sobre el compromiso de los } \\
\text { docentes: un estudio multinivel }\end{array}$ & $\begin{array}{l}\text { Andrea Horn; } \\
\text { Francisco Murillo }\end{array}$ & 2016 & Psicoperspectivas \\
\hline $\begin{array}{l}\text { Liderazgo directivo y condiciones } \\
\text { para la innovación en escuelas } \\
\text { chilenas: el que nada hace, nada } \\
\text { teme }\end{array}$ & $\begin{array}{l}\text { Francisco Leal; } \\
\text { Mario Albornoz; } \\
\text { María Isabel Rojas }\end{array}$ & 2016 & 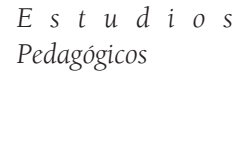 \\
\hline $\begin{array}{l}\text { Novice principals in Chile } \\
\text { mobilizing change for the first } \\
\text { time: Challenges and opportunities } \\
\text { associated with a school's readiness } \\
\text { for change }\end{array}$ & $\begin{array}{l}\text { Sergio Galdames; } \\
\text { C a r m e n } \\
\text { Montecinos; } \\
\text { Fabián Campos; } \\
\text { Luis Ahumada; } \\
\text { María Verónica } \\
\text { Leiva }\end{array}$ & 2017 & $\begin{array}{l}\text { Education al } \\
\text { Management } \\
\text { Administration } \varepsilon \\
\text { Leadership }\end{array}$ \\
\hline $\begin{array}{l}\text { Liderazgo para la mejora en escuelas } \\
\text { vulnerables: prácticas asociadas } \\
\text { al cumplimiento de metas de } \\
\text { aprendizaje }\end{array}$ & $\begin{array}{l}\text { Viola Espínola; } \\
\text { Ernesto Treviño; } \\
\text { M a g d a l e n a } \\
\text { Guerrero, José } \\
\text { Martínez }\end{array}$ & 2017 & 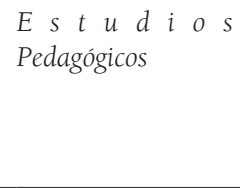 \\
\hline $\begin{array}{l}\text { Liderazgo distribuido y aprendizaje } \\
\text { de la matemática en escuelas } \\
\text { primarias: el caso de Chile }\end{array}$ & $\begin{array}{l}\text { Pablo López; } \\
\text { Verónica Gallegos }\end{array}$ & 2017 & Perfiles Educativos \\
\hline $\begin{array}{l}\text { Comparative study of school } \\
\text { principals' leadership practices: } \\
\text { lessons for Chile from a cross- } \\
\text { country analysis }\end{array}$ & $\begin{array}{l}\text { Javiera Marfán; } \\
\text { Javier Pascual }\end{array}$ & 2017 & $\begin{array}{l}\text { Educational } \\
\text { Management } \\
\text { Administration } \varepsilon \\
\text { Leadership }\end{array}$ \\
\hline $\begin{array}{l}\text { Liderazgo escolar y conflictos } \\
\text { socioeducativos. un estudio } \\
\text { exploratorio en liceos públicos } \\
\text { chilenos }\end{array}$ & $\begin{array}{l}\text { C r i s t ó b a l } \\
\text { Villalobos; Javiera } \\
\text { P e ñ a; E lis a } \\
\text { Aguirre; Magdalena } \\
\text { Guerrero }\end{array}$ & 2017 & $\begin{array}{l}\text { Calidad en la } \\
\text { Educación }\end{array}$ \\
\hline
\end{tabular}

Claudio Barrientos; 2016 REICE

Patricia Silva;

Serafín Antúnez

(1)




\begin{tabular}{|c|c|c|c|}
\hline $\begin{array}{l}\text { Influencia de las prácticas de } \\
\text { liderazgo pedagógico en las } \\
\text { prácticas pedagógicas docentes: } \\
\text { caso en Chile de las UTP }\end{array}$ & $\begin{array}{l}\text { G u i } 1 \text { l e r m o } \\
\text { Rodríguez; Joaquín } \\
\text { Gairín }\end{array}$ & 2017 & $\begin{array}{l}\text { International } \\
\text { Journal of } \\
\text { Educational } \\
\text { Leadership } E \\
\text { Management }\end{array}$ \\
\hline $\begin{array}{l}\text { Jefes de UTP nóveles en Chile: } \\
\text { desafíos del liderazgo pedagógico }\end{array}$ & $\begin{array}{l}\text { Marta Quiroga; } \\
\text { Felipe Aravena }\end{array}$ & 2017 & $\begin{array}{l}\text { Perspectiva } \\
\text { Educacional. } \\
\text { Formación de } \\
\text { Profesores. }\end{array}$ \\
\hline $\begin{array}{l}\text { Destructive leadership behavior: An } \\
\text { exploratory study in Chile }\end{array}$ & Felipe Aravena & 2017 & $\begin{array}{l}\text { Leadership and } \\
\text { policy in schools }\end{array}$ \\
\hline $\begin{array}{l}\text { Creencias de directivos escolares: } \\
\text { implicancias en el liderazgo } \\
\text { pedagógico }\end{array}$ & $\begin{array}{l}\text { María Elena } \\
\text { Mellado; Juan } \\
\text { Carlos Chaucono; } \\
\text { Carolina Villagra }\end{array}$ & 2017 & $\begin{array}{l}\text { Psicología Escolar e } \\
\text { Educacional }\end{array}$ \\
\hline $\begin{array}{l}\text { Relational trust and positional } \\
\text { power between school principals } \\
\text { and teachers in Chile: A study of } \\
\text { primary schools }\end{array}$ & $\begin{array}{l}\text { José Weinstein; } \\
\text { Dagmar Raczynski; } \\
\text { Javiera Peña }\end{array}$ & 2018 & $\begin{array}{l}\text { Educational } \\
\text { Management } \\
\text { Administration } E \\
\text { Leadership }\end{array}$ \\
\hline $\begin{array}{l}\text { Construcción y pérdida de la } \\
\text { confianza de docentes: Un análisis } \\
\text { de incidentes críticos }\end{array}$ & $\begin{array}{l}\text { Javiera Peña; José } \\
\text { Weinstein; Dagmar } \\
\text { Raczynski }\end{array}$ & 2018 & Psicoperspectivas \\
\hline $\begin{array}{l}\text { Moving the school forward: } \\
\text { Problems reported by novice and } \\
\text { experienced principals during a } \\
\text { succession process in Chile }\end{array}$ & $\begin{array}{l}\text { C a r m e n } \\
\text { Montecinos; Tony } \\
\text { Bush; Felipe } \\
\text { Aravena }\end{array}$ & 2018 & $\begin{array}{l}\text { International } \\
\text { Journal of } \\
\text { Educational } \\
\text { Development }\end{array}$ \\
\hline $\begin{array}{l}\text { ¿Cuán preparados llegan los } \\
\text { directores escolares?: un análisis } \\
\text { sobre su formación y trayectorias } \\
\text { laborales previas a ejercer su cargo }\end{array}$ & $\begin{array}{l}\text { Rosario Rivero; } \\
\text { Con s t a n z a } \\
\text { Hurtado; Ángeles } \\
\text { Morandé }\end{array}$ & 2018 & $\begin{array}{l}\text { Calidad en la } \\
\text { Educación }\end{array}$ \\
\hline $\begin{array}{l}\text { Los directivos escolares como } \\
\text { informantes cualificados de las } \\
\text { políticas educativas. Sus opiniones } \\
\text { bajo el gobierno de Michelle } \\
\text { Bachelet en Chile (2014-2017) }\end{array}$ & $\begin{array}{l}\text { José Weinstein; } \\
\text { Gonzalo Muñoz; } \\
\text { Rosario Rivero }\end{array}$ & 2018 & REICE \\
\hline $\begin{array}{l}\text { Bicephalous leadership structure: } \\
\text { An exploratory study in Chile }\end{array}$ & $\begin{array}{l}\text { Felipe Aravena; } \\
\text { Marta Quiroga }\end{array}$ & 2018 & $\begin{array}{l}\text { International } \\
\text { Journal of } \\
\text { Leadership in } \\
\text { Education }\end{array}$ \\
\hline $\begin{array}{l}\text { The new teaching career policy in } \\
\text { Chile: Perspectives from school } \\
\text { principals }\end{array}$ & $\begin{array}{l}\text { Marta Quiroga; } \\
\text { Felipe Aravena }\end{array}$ & 2018 & $\begin{array}{l}\text { KEDI Journal of } \\
\text { Educational Policy }\end{array}$ \\
\hline
\end{tabular}


An ineffective preparation? The José Weinstein, scarce effect in primary school Ariel Azar and principals' practices of school Joseph Flessa leadership preparation and training in seven countries in Latin America

\begin{tabular}{lll}
\hline El liderazgo escolar hacia el Fancy Castro; 2018 Revista de \\
modelamiento de una cultura Verónica Alarcón & Investigación \\
escolar inclusiva y de altas & Educativa de \\
expectativas & la Escuela de \\
& Graduados en \\
& Educación
\end{tabular}

La respuesta de directores escolares ante las políticas de inclusión Marta Quiroga; Felipe Aravena 2018 Calidad en la escolar en Chile

Prácticas de gestión de los equipos Sebastián Donoso; directivos de escuelas públicas Nibaldo Benavides chilenas

\begin{tabular}{llrl}
\hline $\begin{array}{l}\text { School middle leaders in Australia, } \\
\text { Chile and Singapore }\end{array}$ & $2018 \begin{array}{l}\text { School Leadership } \\
\text { E Management }\end{array}$ \\
\hline $\begin{array}{l}\text { Aprender a liderar el cambio en } \\
\text { organizaciones escolares en Chile }\end{array}$ & $\begin{array}{l}\text { Luis Ahumada; } \\
\text { Montecinos; María } \\
\text { Verónica Leiva; }\end{array}$ & $\begin{array}{l}\text { Investigación en } \\
\text { Fabián Campos }\end{array}$ & $\begin{array}{l}\text { Educación } \\
\text { Internacional de }\end{array}$ \\
\hline $\begin{array}{l}\text { Trabajo duro, una sed por aprender } \\
\text { y un poco de suerte: la trayectoria } \\
\text { laboral de los directores de la } \\
\text { generación milenio en las escuelas } \\
\text { públicas de Chile }\end{array}$ & & Perspectiva \\
\hline
\end{tabular}

2018 Educational Management Administration \& Leadership
2018 Revista Brasileira de Educação

Fuente: Elaboración propia. 